\title{
ПРОБЛЕМНЫЕ ИННОВАЦИИ В УПРАВЛЕНИИ СФЕРОЙ НИОКР: ИСПОЛЬЗОВАНИЕ БИБЛИОМЕТРИЧЕСКИХ ПОКАЗАТЕЛЕЙ
}

\author{
Варшавский А.Е.
}

В работе с критических позиций рассмотрены вопросы управления научными организачиями на основе непродуманного использования библиометрических показателей для оченки результативности ученых. Сомнительность метода оченки научного результата ученых и организачий с помощью количественных показателей, заимствованного в США и других странах, где он стал прежде всего использоваться в вузах, его негативное влияние на развитие науке, уже более десяти лет отмечается зарубежными учеными, предлагающими опираться на экспертные оценки. В статье еще раз напоминается о иелесообразности применения стандартного метода экономической оценки эффективности труда ученых. Подчеркивается также необходимость использования точных статистических данных, так как основная проблема для российской науки - негативная тенденция сокращения числа исследователей, отличная от общемировой тенденции роста научного потенциала, а использование завышенных данных о численности научных работников в эквиваленте полного рабочего времени искажает реальную картину. Кроме того, актуально и исключение двойного счета при анализе результативности научной деятельности в вузах.

DOI: $10.20537 /$ mce2020econ06

Введение. Предложенная Министерством науки и высшего образования Российской Федерации Методика «Комплексный балл публикационной результативности» для научных организаций, подведомственных Министерству, на 2020 год, еще более возбудила критику использования технологии расчета результативности научных организаций на основе публикаций в базах данных Web of Science и Scopus. Как отмечается Министерством, основной особенностью этой методики «является использование фракционного счета-метода, который разделяет вклад авторов и организаций в научный результат, и качества журналов - категории, которую определяет уровень цитируемости журнала». 
Данная методика определяет способ расчета значения качественного показателя, характеризующего публикационную результативность научных организаций, находящихся в ведении Минобрнауки России, при формировании государственного задания на проведение фундаментальных и поисковых научных исследований.

В открытом письме Ученого совета Института философии РАН Президенту РФ справедливо дается негативная оценка этой проблемной инновации в управлении с точки зрения развития социогуманитарной сферы. В [1] справедливо отмечается, что при этом не будут учитываться многие журналы, индексируемые в РИНЦ, а высшая оценка в базе Web of Science по баллам будет в 40 раз выше, чем статьи в ВАКовском журнале. При этом, согласно методике, книгам дается 1 балл, как обычной статье, потому что чиновники не знают, как выделить книги, представляющие ценность для науки (очевидно, не только из-за невозможности прочитать все книги и оценивать их, но также из-за непонимания того, что в них написано).

Подобные методики являются проблемными инновациями в управлении наукой. Они создаются чиновниками, не имеющими других возможностей для управления наукой, кроме использования количественных показателей, несмотря на то, что в мировой практике в последние годы возвращаются к тому, чтобы учитывать экспертные оценки при анализе качества научных работ (так же, как это делалось в нашей стране ранее) и отказываются от библиометрических показателей при выделении финансовых ресурсов на НИОКР. Серьезной проблемой является и предпочтение статей, написанных на английском языке (эта проблема, возможно, исчезнет после того, как будут созданы полноценные высококачественные программы-переводчики, - следует отметить, что в последние годы наблюдается большой прогресс в этом направлении, - но пока об этом говорить рано, особенно в том, что относится к социогуманитарной области).

В данной статье рассмотрены вопросы некорректного использования библиометрического метода для оценки результативности труда научных работников. Показано, что более оправдано применение традиционного метода расчета экономической оценки эффективности, который дает более объективные результаты. Рассмотрена также проблема двойного счета при анализе результативности научной деятельности в вузах. 
Некорректное использование библиометрического метода. О некорректном использовании библиометрического метода для оценки результативности труда научных работников говорится уже много лет (см., например, [2-5]). В последние годы за рубежом еще более увеличилось число специалистов, которые отмечают, что библиометрические методы используются неправильно.

Показательным является мнение Д. Пендлбери (D. Pendlebury), который был аналитиком цитирования в компании Clarivate Analytics, paнее бывшей подразделением компании Thomson Reuters. Он считает, что библиометрический подход был неправильно понят или неправильно использован многими заинтересованными органами управления в сфере НИОКР - такими, как директивные органы и комитеты по предоставлению грантов и т.П. (см. интервью с Д. Пендлбери [6]).

Внедрение упрощенной, единой системы мер для оценки и предоставления грантов (такой как индекс Хирша или импакт-фактор) очень часто подрывает уверенность в полезности и ценности библиометрического анализа и изменяет поведение ученых, которые в результате нацеливаются на достижении определенных показателей, а не сосредотачиваются на своих исследованиях. По его мнению, это очень вредно для науки. Для защиты от такого злоупотребления необходимо, чтобы анализ цитирования был дополнением к экспертной оценке, а не ее заменой, так как только эксперты могут определить содержание и качество работы, в то время как библиометрические показатели играют вспомогательную роль и не доказывают значимость или ценность работы.

В то же время библиометрические методы позволяют отслеживать влияние фундаментальных и прикладных исследований на инновации. Одним из важных направлений в настоящее время в США является анализ научной литературы, цитируемой наиболее ценными патентами, который позволяет выявить определенные связи между университетской наукой и промышленностью. В свою очередь, это позволяет стимулировать развитие тех направлений исследований, которые оказали влияние на инновационную сферу, что, однако, не означает поддержки только тех, у кого высокие показатели цитируемости. Другими словами, данный метод с успехом может быть использован для научно-технической разведки и прогнозирования будущих прорывов в области технологии и техники.

Следует упомянуть и исследование, проведенное в [7], где даются доказательства запоздалого признания новых статей, так как они с меньшей вероятностью будут цитироваться в краткосрочной перспекти- 
ве, причем такие статьи чаще публикуются в журналах с более низким импакт-фактором. По мнению авторов, это свидетельствует о том, что научная политика, в частности решения о финансировании, которые опираются на библиометрические показатели, основанные на краткосрочном количестве цитируемости и факторах влияния журнала, могут быть предвзяты в отношении новых исследований, характеризующихся показателями «высокого риска/высокой прибыли». При этом полученные в данной работе результаты предостерегают также от монодисциплинарного подхода в оценке истинной ценности новых исследований.

Можно сослаться также на мнение профессора теоретической физики Ганноверского университета Р. Вернера, опубликованное в журнале Nature [8], который считает, что фокусирование внимания на библиометрических показателях делает научные статьи менее полезными и что ученые должны противостоять тенденции использования показателей библиометрии в качестве основы в процессах принятия решений, так как статьи должны оцениваться по научным заслугам, а не по журнальному импакт-фактору. Он подчеркивает, что библиометрия оказывает катастрофическое воздействие на модель науки, предстающую перед молодыми исследователями, так как при ориентации их мотивации на достижение количественных показателей более предпочтительным становится выбор хорошо оплачиваемой специальности банкира.

Следует отметить, что библиометрические, т.е. количественные методы начали применяться для оценки результативности научных работников в университетах США. В вышедшей в 2018 г. в США и переведенной у нас в 2019 г. книге Дж. Мюллера [9] большое внимание уделяется проблемам, связанным с использованием количественных показателей, причем отмечается, что их применение связано с организацией научных исследований в вузах, так как для оценки научной продуктивности университетов используется количество научных публикаций.

Автор обращает внимание на то, что стимулирование повышения количества публикаций, а не качества, ведет к увеличению скорости их подготовки, тогда как для написания книги могут потребоваться годы. В результате происходит снижение числа работ высокого уровня. Оценка исключительно по количественным показателям ведет к росту быстрых публикаций, она не стимулирует развитие перспективных долгосрочных исследований, нацеливает на быстрое получение краткосрочных, второстепенных результатов (некоторые эксперты даже рекомендуют, в противовес этому, ограничить ученых публикацией только одной статьи в 
год). При этом использование показателей цитируемости ведет к тому, что ученые для повышения цитируемости своих работ договариваются упоминать работы друг друга как можно чаще, а журналы требуют от авторов принятых работ давать ссылки на опубликованные ранее в них статьи с целью повышения своего «импакт-фактора».

Стремление использовать количественные показатели в этой книге объясняется следующим.

Во-первых, возросло недоверие к мнению экспертов, причем руководство учреждений в свою очередь стало использовать количественные показатели для собственной защиты и доказательства эффективности своей работы. В США стремление все документировать, опираясь на количественные показатели, было вызвано боязнью судебного преследования в результате расширения гражданских прав.

Во-вторых, недоверие к государственным институтам было связано и с отсутствием «финансового результата» с помощью которого можно было бы оценить эффективность деятельности, из-за чего требовались количественные критерии.

В-третьих, возрастание сложности организации вузов, государственных учреждений привело к тому, что их руководители должны принимать решения в условиях ограниченного времени и больших объемов информации. Это также стимулировало использование количественных показателей. Отсюда и стремление руководства к значительному расширению отчетности. Кроме того, резко возросла мобильность руководящих кадров, которые чаще, чем это было раньше, переходят из одной организации в другую (примером у нас могут быть так называемые «эффективные менеджеры», в том числе работающие в Минобрнауки и др.). При ограниченных представлениях о новых для себя организациях они больше полагаются на количественные показатели, причем аналогичные тем, которые они использовали на прежней работе.

Наконец, существенным фактором является развитие информационных технологий, в частности, программных продуктов, при использовании которых исполнителям приходится тратить много рабочего времени.

Можно отметить также и стремление к использованию рейтингов. Например, в недавно вышедшей книге [10] рассмотрены проблемы, связанные ранжированием в области спорта, искусства, науки, политики и т.д. Популярность ранжирования автор объясняет с позиций нейробиологии, нейрохимических процессов, управляющих, по его мнению, психологическим и социальным поведением. Он рассматривает источники 
когнитивных предубеждений, утверждая, что они являются основными причинами того, что выбор не является строго рациональным, а подчиняется также некоторым правилам, которые связаны с желанием влиять на чей-либо выбор или избежать чужого влияния. Это означает, что ранжирование может привести к ошибочным решениям как из-за предвзятости лица, принимающего решение, так и отсутствия понимания проблемы, либо желания манипулировать результатом для своей выгоды.

Следует еще раз напомнить и заявление Правления директоров крупнейшей в мире профессиональной ассоциации, широко известного Института инженеров электротехники и электроники, выпускающего более 100 рецензируемых журналов (IEEE - Institute of Electrical and Electronics Engineers) от 9 сентября 2013 г. В нем отмечается: «почти все библиометрические индексы возможно использовать для измерения популярности или престижа, .... для оценки научного влияния научной организации, если имеющиеся данные позволяют провести статистически значимый анализ...; нельзя оценивать уровень статьи по популярности журнала, в котором она опубликована, так как даже в лучших журналах встречаются слабые публикации...; нельзя использовать библиометрию для индивидуальной оценки ученого. Хотя библиометрия может быть использована как источник дополнительной информации для определения качества исследований в определенной области, основным способом для анализа качества научноисследовательского проекта или отдельного ученого должна быть экспертная оценка, которая в первую очередь учитывает научное содержание работы» [11].

Кроме того, при проведении межстранового сопоставления количественных библиометрических показателей необходимо учитывать преимущество англоязычных стран в публикационной активности. Об этом свидетельствует разработанная в статье [12] для 30 стран эконометрическая модель, с помощью которой показано, что библиометрический показатель «число научных статей на 1 млн. человек населения» в англоязычных странах значительно выше, чем у неанглоязычных.

Целесообразность применения экономической оценки эффективности труда ученых. Уже более 15 лет тому назад было показано в наших работах, см. $[2,5,13]$ и затем отдельными учеными за рубежом [14], что целесообразнее эффективность (результативность или продуктивность) труда ученых оценивать по показателю «число статей в расчете 
на единицу внутренних затрат на науку по паритету покупательной способности (ППС)» - так, как это принято в экономических расчетах при оценке эффективности, где оценивается результат на единицу затрат.

Межстрановые сопоставления свидетельствуют, что по среднему числу публикаций в год в расчете на 1 млн долл. среднегодовых затрат на НИОКР по ППС за период 2010-2014 гг. в ценах 2015 г. Россия (0.77 публикации на 1 млн долл.) опережает США и Южную Корею (по 0.68 публикаций), Японию (0.46), Китай (0.6 публикации на 1 млн долл.) и не значительно отстает от Германии, см. табл. 1. Таким образом, с помощью данного показателя эффективности можно увидеть, что результативность российских ученых не хуже и даже выше, чем ученых ряда наиболее развитых стран (следует отметить, что приведенные данные в незначительно зависят от того, в ценах какого года рассчитываются затраты на науку по ППС).

Таблица 1. Среднее число публикаций в год за период 2010-2014 гг. в расчете на 1 млн долл затрат на НИОКР по ППС в ценах 2015 г. Расчет по данным ЮНЕСКО (2016 г.) и ОЕСD (2020 г.).

\begin{tabular}{|l|c|c|}
\hline & $\begin{array}{c}\text { Среднее число публикаций в год (2010- } \\
\text { 2014 гг.) в расчете на 1 млн долл затрат } \\
\text { на НИОКР по ППС в ценах 2015 г. }\end{array}$ & $\begin{array}{c}\%, \\
\text { Россия=100\% }\end{array}$ \\
\hline Великобритания & 2.02 & 262.0 \\
\hline Франция & 1.08 & 140.4 \\
\hline Германия & 0.85 & 110.2 \\
\hline Россия & 0.77 & 100.0 \\
\hline США & 0.68 & 87.9 \\
\hline Южная Корея & 3.4 & 88.7 \\
\hline Китай & 0.60 & 77.9 \\
\hline Япония & 0.46 & 59.4 \\
\hline
\end{tabular}

\section{Необходимость использования точных статистических данных.}

Основная проблема - негативная тенденция сокращения числа исследователей в России, отличная от общемировой тенденции роста научного потенциала. Численность исследователей в номинальном исчислении (headcount) значительно возросла по данным OECD практически во всех странах. Например, за 20 лет в период 1997-2017 гг.: в Южной Корее, Турции и Сингапуре она увеличилась в 3.5-3.8 раза, в Чешской Республике, Польше, Венгрии и Литве - примерно в 2 раза, в 
Италии, Испании и Франции - также в 2 раза и более, с начала 2000-х гг. в Германии и Великобритании она возросла примерно в 1.5 раза и в Японии - в 1.2 раза.

Однако в России, в отличие от других стран, в 2017 г. численность исследователей оказалась меньше на $26 \%$, чем в 1997 г. и на $41 \%$ - по сравнению с 1995 г., см. табл. 2.

Преодоление этой негативной тенденции, усугубляемой низкой долей затрат на науку (всего около 1.1\% ВВП), наиболее важно для России, и именно ее в первую очередь необходимо учитывать при выборе методов управления наукой, для обеспечения преемственности знаний.

Таблица 2. Изменение численности исследователей в номинальном исчислении (headcount) за 20 лет в 1997-2007 гг. по странам; источник: данные OECD.

\begin{tabular}{|l|c|c|c|}
\hline Страна & $\mathbf{1 9 9 7}$ г. & $\mathbf{2 0 1 7}$ г. & $\mathbf{2 0 1 7 / 1 9 9 7 , \%}$ \\
\hline Япония & $792699^{*}$ & 930720 & 117.4 \\
\hline Германия & $397130 * *$ & 623125 & 156.9 \\
\hline Великобритания *** & 364807 & 510980 & 140.1 \\
\hline Южная Корея & 138438 & 482796 & 348.7 \\
\hline Франция & 197032 & 416217 & 211.2 \\
\hline Россия & $\mathbf{4 5 5 1 0 8}$ & $\mathbf{3 5 9 7 9 3}$ & $\mathbf{7 9 . 1}$ \\
\hline Испания & $\mathbf{5 1 8 6 9 0 * * * *}$ & & $\mathbf{6 9 . 4}$ \\
\hline Турция & 103905 & 225995 & 217.5 \\
\hline Италия & 54577 & 210769 & 386.2 \\
\hline Польша & 99571 & 195560 & 196.4 \\
\hline Чешская Республика & 86309 & 187905 & 217.7 \\
\hline Сингапур & 27444 & 59789 & 217.9 \\
\hline Венгрия & 11302 & 42769 & 378.4 \\
\hline Литва & 21999 & 42729 & 194.2 \\
\hline *2001 г., **2003 г. ***данные за 2005 и 2016 гг. ****1995 г. & 18767 & 186.6 \\
\hline
\end{tabular}

Завышенные данные о численности научных работников в эквиваленте полного рабочего времени (FTE). Необходимо учитывать неточность (из-за двойного счета) оценки показателя FTE, которая предоставляется в OECD (статистика FTE считается основной при межстрановых сопоставлениях).

Важно отметить, что, как указывается в руководстве Frascati, одному исследователю может соответствовать значение этого показателя не более 1 в год, хотя некоторые исследователи работают в нескольких 
научных организациях. При этом этот показатель незначим, если он меньше 0.1 , т.е. если исследователь тратит менее 0.1 времени в год на НИОКР, то он не учитывается в общей численности по показателю FTE. Таким образом, полагается, что показатель FTE всегда меньше или равен и, во всяком случае, никак не может превышать показатель номинальной численности исследователей (headcount) как для работающих в организации, так и для совместителей или временных работников. Например, если человек работает 6 месяцев в году, то он учитывается как 0.5 FTE. Следует учитывать также, что по методологии OECD в число исследователей включаются и аспиранты, ведущие научную работу $\mathrm{PhD}$ (ISCED level 7).

Однако в данных, приводимых OECD для России, уже много лет численность исследователей в расчете по FTE больше, чем в номинальном исчислении (headcount, by heads), что свидетельствует о двойном счете.

В результате, если при использовании номинального показателя Россия по численности исследователей находится на 8-м месте (после США, Китая, Японии, Германии, Великобритании, Южной Кореи и Франции, см. табл. 3), то по показателю FTE - на 5 месте, а по численности занятых НИОКР на 4 месте. При этом по показателю FTЕ численность исследователей у нас примерно такая же, что у Германии, но номинальной численности исследователей в 1.73 раза меньше.

Если же использовать соотношение численности по FTЕ к номинальной как у других стран (что более правильно), то численность исследователей в России по FTE будет значительно меньше: так, если это соотношение равно 0.8 (как, например, у Южной Кореи), то мы получим примерно 288 тыс. человек, если 0.7 (примерно как у Германии), то 252 тыс. по FTE, что ближе к Испании и Турции.

Очевидно, такое расхождение приводит к неверным выводам при принятии управленческих решений. Оно создает неправильное представление о завышенных размерах человеческого потенциала российской науки (см., например, Предложения Счетной палаты РФ [15], которые опираются на этот показатель) и способствует выводам о недостаточной результативности ученых, а также предложениям о сокращении их численности в нашей стране. 
Таблица 3. Численность исследователей headcount (номинальная) и FTE, человек, и соотношение численности в эквиваленте полного рабочего времени и номинальной численности исследователей по странам, 2017; источник: данные OECD (10 стран из 37).

\begin{tabular}{|r|l|c|c|c|}
\hline № & Страна & $\begin{array}{c}\text { Численность ис- } \\
\text { следователей в } \\
\text { Эквиваленте пол- } \\
\text { ного рабочего } \\
\text { времени (FTE), } \\
2017 \text { г. }\end{array}$ & $\begin{array}{c}\text { Номинальная } \\
\text { численность } \\
\text { исследователей } \\
\text { (headcount), } \\
2017 \text { г. }\end{array}$ & $\begin{array}{c}\text { FTE / } \\
\text { headcount, } \\
\%\end{array}$ \\
\hline 1 & Китай & 1740442 & $\ldots$ & $\ldots$ \\
\hline 2 & США & 1434415 & $\ldots$ & $\ldots$ \\
\hline 3 & Япония & 676292 & 930720 & 72.7 \\
\hline 4 & Германия & 419617 & 623124 & 67.3 \\
\hline 5 & Великобритания & 289674 & 510980 & 56.7 \\
\hline 6 & Корея & 383100 & 482796 & 79.4 \\
\hline 7 & Франция & 295754 & 416217 & 71.1 \\
\hline 8 & Россия & 410617 & $\mathbf{3 5 9 7 9 3}$ & $\mathbf{1 1 4 . 1}$ \\
\hline 9 & Испания & 133213 & 225995 & 58.9 \\
\hline 10 & Турция & 111893 & 210769 & 53.1 \\
\hline
\end{tabular}
*2016 г.

Необходимость исключения двойного счета при анализе результативности научной деятельности в вузах. В настоящее время значительную часть в профессорско-преподавательском составе вузов составляют совместители. По данным ВШЭ [16] в 2013/2014 гг. численность профессорско-преподавательского состава образовательных организаций высшего образования составляла (на начало учебного года) 407.6 тыс. человек, в том числе штатного профессорскопреподавательского состава (без внешних совместителей) 319.3 тыс. (78.3\%), профессорско-преподавательского состава, работающего на условиях внешнего совместительства - 86.3 тыс. $(21.2 \%)$ и иностранных преподавателей и специалистов - 2 тыс. (0.5\%), см. табл. 4. 
Таблица 4. Численность профессорско-преподавательского состава образовательных организаций высшего образования (на начало учебного года). Источник: [16].

\begin{tabular}{|l|c|c|c|c|c|c|}
\hline & \multicolumn{2}{|c|}{$2000 / 2001$} & \multicolumn{2}{|c|}{$2010 / 2011$} & \multicolumn{2}{|c|}{$2013 / 2014$} \\
\hline & $\begin{array}{c}\text { тыс. } \\
\text { человек }\end{array}$ & $\%$ & $\begin{array}{c}\text { тыс. } \\
\text { человек }\end{array}$ & $\%$ & $\begin{array}{c}\text { тыс. } \\
\text { человек }\end{array}$ & $\%$ \\
\hline $\begin{array}{l}\text { Профессорско- } \\
\text { преподавательский состав } \\
\text { (без внешних совместителей) }\end{array}$ & 279.6 & 78.1 & 356.8 & 76.7 & 319.3 & 78.3 \\
\hline $\begin{array}{l}\text { Профессорско- } \\
\text { преподавательский состав, } \\
\text { работающий на условиях } \\
\text { внешнего совместительства }\end{array}$ & 78.4 & 21.9 & 107.5 & 23.1 & 86.3 & 21.2 \\
\hline $\begin{array}{l}\text { Численность иностранных } \\
\text { преподавателей и специа- } \\
\text { листов }\end{array}$ & 358 & 100 & 465.3 & 100 & 407.6 & 100 \\
\hline $\begin{array}{l}\text { Профессорско- } \\
\text { преподавательский состав, } \\
\text { всего, тыс. человек }\end{array}$ & & 1 & 0.2 & 2 & 0.5 \\
\hline
\end{tabular}

При этом доля совместителей - докторов наук в Москве составляла $47.2 \%$, а в филиалах ВШЭ была значительно выше $50 \%$, что вполне объяснимо. Например, в Санкт-Петербурге она составляла $76.5 \%$. Очевидно, такую структуру преподавателей необходимо учитывать при анализе результативности научной деятельности вузов, оцениваемой по количеству статей, см. табл. 5.

Как показывает практика, все вузы требуют от преподавателейсовместителей перечень статей, якобы подготовленных во время учебного процесса. Как правило, при этом вузы требуют, чтобы статьи были аффилированы у них. Преподаватели-совместители (как правило, это научные сотрудники РАН и отраслевых научных организаций) обычно идут на это, чтобы не лишиться дополнительного заработка и должности в вузе, а также из чисто альтруистических соображений, не отдавая себе отчета в том, что такая практика косвенно ведет к снижению роста финансирования научных учреждений, в штате которых они числятся. 
Варшавский А.Е. Проблемные инновации в управлении сферой НИОКР.., стр. 56-72 Varshavsky A.E. Questionable innovations in R\&D management..., pp. 56-72

Таблица 5. Численность и соотношение штатных преподавателей ВШЭ и совместителей, 2009-2010 гг. Источник: [17]

\begin{tabular}{|c|c|c|c|c|c|c|c|c|}
\hline & \multicolumn{4}{|c|}{ Численность преподавателей } & \multicolumn{4}{|c|}{$\%$} \\
\hline & $\begin{array}{c}\text { без уче- } \\
\text { ной сте- } \\
\text { пени }\end{array}$ & к.н. & д.н. & $\begin{array}{c}\text { Всего } \\
\text { препода- } \\
\text { вателей }\end{array}$ & $\begin{array}{c}\text { без } \\
\text { ученой } \\
\text { степени }\end{array}$ & к.н. & д.н. & \begin{tabular}{|c|} 
Всего \\
препода- \\
вателей
\end{tabular} \\
\hline \multicolumn{9}{|l|}{ Москва } \\
\hline совместители & 256 & 350 & 154 & 760 & 43.2 & 46.3 & 47.2 & 45.4 \\
\hline штатные & 336 & 406 & 172 & 914 & 56.8 & 53.7 & 52.8 & 54.6 \\
\hline Всего & 592 & 756 & 326 & 1674 & 100 & 100 & 100 & 100 \\
\hline \multicolumn{9}{|l|}{ Филиалы } \\
\hline \multicolumn{9}{|l|}{ Пермь } \\
\hline совместители & 48 & 15 & 3 & 66 & 54.5 & 24.6 & 60.0 & 42.9 \\
\hline штатные & 40 & 46 & 2 & 88 & 45.5 & 75.4 & 40.0 & 57.1 \\
\hline Всего & 88 & 61 & 5 & 154 & 100 & 100 & 100 & 100 \\
\hline \multicolumn{9}{|l|}{ Н.Новгород } \\
\hline совместители & 21 & 39 & 20 & 80 & 18.1 & 29.8 & 64.5 & 28.8 \\
\hline штатные & 95 & 92 & 11 & 198 & 81.9 & 70.2 & 35.5 & 71.2 \\
\hline Всего & 116 & 131 & 31 & 278 & 100 & 100 & 100 & 100 \\
\hline \multicolumn{9}{|l|}{$\begin{array}{c}\text { Санкт- } \\
\text { Петербург }\end{array}$} \\
\hline совместители & 89 & 71 & 26 & 186 & 54.3 & 51.1 & 76.5 & 55.2 \\
\hline штатные & 75 & 68 & 8 & 151 & 45.7 & 48.9 & 23.5 & 44.8 \\
\hline Всего & 164 & 139 & 34 & 337 & 100 & 100 & 100 & 100 \\
\hline \multicolumn{9}{|l|}{$\begin{array}{c}\text { Всего Москва } \\
\text { с филиалами }\end{array}$} \\
\hline совместители & 414 & 475 & 203 & 1092 & 43.1 & 43.7 & 51.3 & 44.7 \\
\hline штатные & 546 & 612 & 193 & 1351 & 56.9 & 56.3 & 48.7 & 55.3 \\
\hline Всего & 960 & 1087 & 396 & 2443 & 100 & 100 & 100 & 100 \\
\hline
\end{tabular}

При этом значительно искажаются оценки публикационной активности вузов, причем появляется двойной счет. Так, в исследовании числа публикаций вузов-участников Проекта 5-100, как отмечают авторы статьи, подготовленной сотрудниками ВШЭ [18], «каждой организации, упомянутой в списке аффилиаций той или иной статьи, статья засчитывается полностью, вне зависимости от общего числа аффилиаций». Интересны выводы этой статьи, в которых предполагается, что часть публикаций вузов первой волны была подготовлена до начала программы и «на 
другие средства, а вузы научились демонстрировать «бумажный» рост показателей за счет включения своих аффиляций в работы». Поэтому авторы статьи предлагают дополнить «полный» расчет числа публикаций «дробным», когда каждый балл, присваиваемый публикации, делится между всеми указанными оргакнизациями пропорционально числу авторов из соответствующей организации. При этом они подчеркивают, что такой подход позволит оценить вклад ученых РАН и иностранных соавторов, «приносящих вузам множество публикаций, в том числе в высокоцитируемых журналах» (это подтверждается данными работы [19], где отмечается рост сотрудничества вузов с РАН с $28.5 \%$ в 2010 г. до $34.8 \%$ в 2014 г.).

Кроме того, при значительном увеличении доли средств на научные исследования, проводимые в вузах, необходимо понимать, что прямая обязанность вузов - прежде всего обучение студентов, а не ИР. Еще в 2010 г. в докладе Лиги европейских исследовательских университетов (LERU) (в нее входят 22 ведущих вуза стран EC) отмечалось, что акцент на расширение ИР в университетах может привести к тому, что «наука окажется врагом высшего образования, а не его дополнением». Там же сказано: нужно отказаться от распространенного представления об университете как «о супермаркете, продающем модульные продукты» [20].

Это подтверждается также данными о негативном отношении работодателей к показателю цитируемости, которое было выявлено путем анализа данных рейтинга университетов THE-QS (по данным за 2009 г.) с помощью следующей эконометрической модели [21]:

$$
\mathrm{Y}_{2}=0.5 * \mathrm{Y}_{1}+0.13 * \mathrm{Y}_{3}-0.16 * \mathrm{Y}_{4}+0.27 * \mathrm{Y}_{6}
$$

где $\mathrm{Y}_{2}$ - оценка работодателями вуза, которая зависит от следующих факторов: экспертная оценка $\left(\mathrm{Y}_{1}\right)$, соотношение числа преподавателей и студентов $\left(\mathrm{Y}_{3}\right)$; показатель цитируемости $\left(\mathrm{Y}_{4}\right)$, доля иностранных студентов ( $\left.\mathrm{Y}_{6}\right)$; доля иностранных преподавателей $\left(\mathrm{Y}_{5}\right)$ (в скобках под коэффициентами даны значения Z-статистики). Как видно из приведенного уравнения, минус перед фактором «показатель цитируемости» $\left(\mathrm{Y}_{4}\right)$ свидетельствует о негативном отношении работодателей к вузам, где публикационная активность преподавателей высока, т.е. количество публикаций в расчете на одного преподавателя не только не является важным показателем, но, более того, оказывает отрицательное влияние на оценку уровня подготовки вузом студентов, принимаемых работодателями на работу. 
Заключение. Таким образом, основные выводы сводятся к следующему.

Анализ мнений зарубежных и отечественных экспертов подтверждает необходимость осторожного использования библиометрических показателей для оценки результативности научной деятельности. Для косвенной оценка результативности целесообразно применение традиционного метода расчета экономической оценки эффективности, который дает более объективные результаты. Однако основным остается использование оценки экспертов.

Основной проблемой для российской науки является негативная тенденция сокращения числа исследователей, отличная от общемировой тенденции роста научного потенциала. Эта негативная тенденция, усиливаемая низким уровнем затрат на НИОКР в \% ВВП, является наиболее важной для российской науки, и ее в первую очередь необходимо учитывать при выборе методов управления наукой, обеспечения преемственности знаний.

Необходимо также использование точных статистических данных, так как завышенные данные о численности научных работников в эквиваленте полного рабочего времени (FTE) искажают реальную картину, ведут к неправильным выводам органов госуправления и не способствуют развитию отечественной науки.

Актуальным является также исключение двойного счета при анализе результативности научной деятельности в вузах, который значительно искажает реальные показатели публикационной активности и преуменьшает роль научных организаций академического и отраслевого сектора, составляющих основную часть сети научных учреждений России.

Наконец, при использовании библиометрических показателей нельзя проводить ежегодный подсчет числа статей и, тем более, требовать увеличения темпов роста, - высококачественные работы, монографии и т.п., как правило, требуют большого периода времени, т.е. следует оценивать работу в среднем за 3-5 лет и, кроме того, период от подачи статьи до ее выхода в свет в ведущих журналах составляет 1-2 года и более. 


\section{СПИСОК ЛИТЕРАТУРЫ}

1. Рубцов А. Журнальная имитация: чем опасна новая методика Минобрнауки // PБK. URL: https://www.rbc.ru/opinions/society/11/02/2020/5e4114479a794708flfd4fe1

2. Варшавский A.E. Основные проблемы оценки результативности и эффективности деятельности научных организаций // Научно-практический журнал "Конщепщии". №1(33). 2015. С. 3-8.

3. Иванов В.В., Варшавский А. Е., Маркусова В.А. Библиометрические показатели российской науки и РАН (1997-2007) // Вестник РАН. 2009. №6. C. $164-182$.

4. Варшавский А., Маркусова В. Потрачено с умом. Результативность научного труда в России выше, чем в Америке // Газета «Поиск». 27 мая 2009. № 21. С.14.

5. Варшавский А.Е., Маркусова В.А. Методологические проблемы международного сравнительного анализа результатов научной деятельности. Инновационная политика: Россия и Мир: 2002-2010 / под общ. Ред. Н.И. Ивановой и В.В. Иванова; Российская академия наук. - М.: Наука, 2011. С.407-441.

6. Kulkarni S. Misuse of bibliometric analysis shifts scientists' focus from their research to pursuing scores. Interview with David A. Pendlebury, Jul 18, 2017. URL: https://www.editage.com/insights/misuse-of-bibliometric-analysis-shiftsscientists-focus-from-their-research-to-pursuing-scores

7. Wang J., Veugelers R., Stephanef P. Bias against novelty in science: A cautionary tale for users of bibliometric indicators // Research Policy. October 2017. Volume 46, Issue 8. P. 1416-1436.

8. Werner $R$. The focus on bibliometrics makes papers less useful // Nature, 15 January 2015. V.517. P.245.

9. Мюллер Дюс. Тирания показателей: Как одержимость цифрами угрожает образованию, здравоохранению, бизнесу и власти. М.: Альпина Паблишер, 2019.

10. Erdi P. Ranking - the unwritten rules of the social game we all play. Oxford University Press, New York, 2019, 256 p.

11. Appropriate Use of Bibliometric Indicators for the Assessment of Journals, Research Proposals, and Individuals. (Adopted by the IEEE Board of Directors 9 September 2013). URL:

http://www.iee.org/publications_standards/publications/rights/ieee_bibliometric _statement_sept_2013.pdf

12. Варшавский Л.Е. Исследование влияния качества человеческого капитала на инновационную активность. / Глава 3 / Инновационная ориентация российских экономических институтов / Под ред. В.Е. Дементьева. М.: Книжный дом «ЛИБРОКОМ», 2009. 
13. Инновационный менеджмент в России: вопросы стратегического управления и научно-технологической безопасности / Рук. авторского коллектива В.Л.Макаров, А.Е.Варшавский. М.: Наука 2004.

14. Leydesdorff L., Wagner C. Macro-level Indicators of the Relations between Research Funding and Research Output // Journal of Informetrics. 2009. Vol.3, no.4. P.353-362.

15. Кузнецова Е., Старостина Ю. Счетная палата назвала главные проблемы российской науки // Политика, 07 февраля 2020. URL: https://www.rbc.ru/politics/07/02/2020/5e3c1bf19a7947cce149aa99

16. Образование в Российской Федерации: 2014: статистический сборник. Москва: Национальный исследовательский университет «Высшая школа экономики», 2014.

17. Итоги учебно-методической работы в 2009/2010 учебном году и задачи на 2010/2011 учебный год. Отчет. Ученый совет ГУ-ВШЭ, 26 ноября 2010 г.

18. Польдин О.В., Матвеева Н.Н., Стерлигов И.А., Юдкевич М.М. Публикационная активность вузов: эффект проекта «5-100» // Вопросы образования. 2017. № 2. C.10-35.

19. Иванов В.В., Маркусова В.А., Миндели Л.Э. Государственные инвестиции и публикационная активность вузов: библиометрический анализ // Вестник Российской академии наук. 2016. Том 86, № 7. С. 611-619.

20. Boulton G. University Rankings: Diversity, Excellence and the European Initiative // League of European Research Universities. Advice Paper, Nr.3, June 2010.

21. Варшавский А.Е., Комкина T.А. Анализ двух основных рейтингов университетов // Прикладная эконометрика, 2011. № 3 (23). С.103-111. 


\title{
QUESTIONABLE INNOVATIONS IN R\&D MANAGEMENT: THE USE OF BIBLIOMETRIC INDICATORS
}

\author{
Varshavsky A.E.
}

The issues of management of scientific organizations based on the unreasoned use of bibliometric indicators for evaluating the scientists' productivity are considered from a critical point of view. The questionable method of evaluating the scientific results of scientists and organizations using quantitative indicators, adopted in the USA and other countries, where it was primarily used in universities, its negative impact on the development of science, has been noted by foreign scientists for more than a decade, offering to rely on expert estimates. The article once again recalls the feasibility of using the standard method of economic assessment of the effectiveness of scientists' work. The need to use accurate statistical data is also underlined, since the main problem for the Russian science is the negative trend of reducing the number of researchers, which differs from the global trend of increasing scientific potential; the use of incorrect data on the number of researchers in the full-time equivalent distorts the real picture. It is shown in addition, that it is important to avoid double counting when analyzing the performance of scientific activities in universities. 